\title{
Consequences of Air Pollution on Health: Time to Act Now!!
}

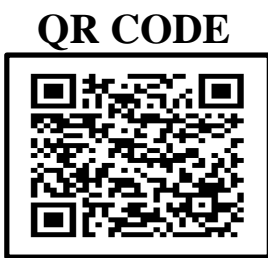

\section{SAGAR UPPAI}

Air pollution has been shown to significantly affect one's health and lead to untimely deaths and unnecessary hospitalizations. Studies have demonstrated a direct association between air pollution and different medical conditions including respiratory and cardiovascular diseases; also, climate change is shown to be associated with air pollution. This short communication addresses the consequences of air pollution on health and request people to act now for a brighter, healthier living due to air free of pollutants.

KEYWORDS: Air Pollution, Asthma, Premature Mortality, Health

\section{INTRODUCTION}

The access of a person/community to clean air and water is a basic human right. However, rapid industrialization coupled with human greed has made our waters polluted and air toxic. This situation has been worse in developing countries exposing various communities to the hazards associated with impure air and water.

As per 2019 estimates, Bangladesh topped the chart with the most polluted air averaging at 83.30 for PM2.5 and very closely followed by Pakistan (Average PM2.5: 65.81) and Mongolia (Average PM2.5: 62.00). The country with the cleanest air was reported to be Bahamas (Average PM2.5: 3.30). ${ }^{1}$ WHO estimates that the menace of air pollution leads of the loss of approximately seven million people across the globe and 9 out of 1o people breathe air that polluted air that exceeds WHO guidelines for clean air. ${ }^{2}$

As stated above, air pollution due to Particulate matter (PM) is a major public health concern especially in urban areas. AS per WHO air quality guidelines, $80 \%$ of the population in Europe reside in areas where PM levels exceed air quality guidelines, as a result of which, their life expectancy is reduced by an average of approximately nine months. ${ }^{3}$ The toxic effects of PM air pollution manifest as cardio-respiratory diseases [MI, stroke, COPD, (lung cancer)], asthmatic exacerbations, cystic fibrosis as well as respiratory infections in children. ${ }^{4}$ The effect of human interests on the increase have been documented by the simulations of Fang et al. who reported that from
1860 (pre-industrial) to 2000 (present day), global Particle Matter (PM2.5) concentrations increased by $5 \%$ due to climate change. ${ }^{5}$

The relation between bad air quality and its effect on health can be both direct and indirect. These particles can affect the cardiopulmonary system, lead to hospitalization due to an increase in respiratory disease (e.g. asthma, chronic bronchitis, rhinitis). ${ }^{6}$ Studies have also documented that environments with high levels of air pollution are responsible for an increased risk of cognitive decline and stroke., ${ }^{7,8}$ Studies have also drawn associations between air pollution and diabetes, ${ }^{9}$ diseases of rheumatic origin, neurodegenerative diseases, preterm birth and decreased reproductive health. ${ }^{10}$

The effects of ambient $\mathrm{NO}_{2}, \mathrm{SO}_{2}$, and PM1o on childhood were studies by Wei et al. Shanghai, China over a 6-year research program and it was indicated that that gestational and lifetime exposures to $\mathrm{NO}_{2}$ were risk factors for atopic eczema in childhood. ${ }^{11}$ Researchers have projected that climate change would increase air pollution-related mortality with the projection having a direct effect on the pollutants.

To combat air pollution, the first WHO Global Conference on Air Pollution and Health was held at Geneva from $1^{\text {st }}$ November 2018; and at the conclusion, participants agreed an aspirational goal of reducing the number of deaths from air pollution by two thirds by 2030. ${ }^{12}$ So much was the emphasis on the reduction of 
air pollution that Air pollution was called by Dr Tedros Adhanom, WHO's Director General as the 'new tobacco'.

Through this short commentary, I would like to invoke all governmental organizations as well as individuals to act promptly by joining hands and work together for the betterment of the community as well as for the health of our future generations.

\section{REFERENCES}

1. IQAIR. World's most polluted countries (online article). Available from: https://www.iqair.com/us/world-most-pollutedcountries [Last Accessed on $25^{\text {th }}$ September, 2020] 2. WHO. Air pollution. (online article). Available from: https://www.who.int/health-topics/air-

pollution\#tab=tab_1 [Last Accessed on $25^{\text {th }}$ September, 2020]

3. World Health Organisation. Health effects of particulate matter: Policy implications for countries in eastern Europe, Caucasus and Central Asia. Copenhagen, Denmark: WHO Regional Office for Europe; 2013

4. Brauer M, Hoek G, Van Vliet P, Meliefste K, Fischer $\mathrm{PH}$, Wijga A, et al. Air pollution from traffic and the development of respiratory infections and asthmatic and allergic symptoms in children. Am J Respir Crit Care Med. 2002;166:1092-8.

5. Fang Y, Naik V, Horowitz LW, Mauzerall DL. Air pollution and associated human mortality: the role of air pollutant emissions, climate change and methane concentration increases from the preindustrial period to present. Atmos Chem Phys. 2013;13(3):1377-94. doi: 10.5194/acp-13-1377-2013.

6. WHO. Review of evidence on health aspects of air pollution-REVIHAAP project: technical report. Copenhagen: WHO Regional Office for Europe; 2013 7. Power MC, Kioumourtzoglou MA, Hart JE, Okereke OI, Laden F, Weisskopf MG. The relation between past exposure to fine particulate air pollution and prevalent anxiety: observational cohort study. BMJ 2015;350, h111. http://dx.doi.org/ 10.1136/bmj.h1111.

8. Genc S, Zadeoglulari Z, Fuss SH, Genc K. The adverse effects of air pollution on the nervous system. J. Toxicol.

http://dx.doi.org/10.1155/2012/782462

9. Thiering E, Heinrich J. Epidemiology of air pollution and diabetes. Trends Endocrinol Metab. 2015;26(7):384-94.

10. Hansen C, Luben TJ, Sacks JD, Olshan A, Jeffay S, Strader L, Perreault SD. The effect of ambient air pollution on sperm quality. Environ Health Perspect. 2010;118(2):203-9.

11. Liu W, Huang C, Hu Y, Fu Q, Zou Z, Sun C, et al. Associations of gestational and early life exposures to ambient air pollution with childhood respiratory diseases in Shanghai, China: A retrospective cohort study. Environ. Int. 2016;572:34-42.

12. WHO. First WHO Global Conference on Air Pollution and Health, 30 October - 1 November 2018. (Online Article) https://www.who.int/airpollution/events/conference/ en/ [Last Accessed on $25^{\text {th }}$ September, 2020]
Source of support: Nil, Conflict of interest: None declared
Cite this article as:

Uppal S Consequences of Air Pollution on Health: Time to Act Now!!. Int Healthc Res J. 2020;4(8):SC1-SC2. https://doi.org/10.26440/IHRJ/0408.11357 